\title{
AKTIVITAS EKSTRAK DAUN KELOR (MORINGA OLEIFERA) TERHADAP KADAR KOLESTEROL TIKUS JANTAN SPRAGUE DAWLEY
}

\author{
Gita Susanti \\ Program Studi S1 Farmasi Sekolah Tinggi Ilmu Kesehatan Siti Khadijah Palembang \\ Email : gita_xf@yahoo.com
}

\begin{abstract}
ABSTRAK
Latar Belakang Kolesterol adalah suatu zat lemak yang dibuat di dalam hati dan lemak jenuh dalam makanan. Jika kadar kolesterol dalam darah terlalu tinggi, maka akan semakin meningkatkan faktor resiko terjadinya penyakit arteri koroner. Tujuan Penelitian untuk mengetahui aktivitas ekstrak daun kelor (Moringa oleifera) dalam menurunkan kadar kolesterol pada tikus jantan Sprague dawley. Metode Penelitian ini merupakan penelitian eksperimental secara in vivo menggunakan rancangan pre- and post- test group design pada bulan November-Desember 2019. Subjek penelitian adalah 30 ekor tikus jantan Sprague dawley yang dibagi dalam 5 kelompok. Kelompok 1 diberikan CMC 0,5\% dan kelompok 2 diberikan simvastatin $0,18 \mathrm{mg}$. Kelompok uji yaitu kelompok 3 diberikan ekstrak dosis 36,4 $\mathrm{mg} / \mathrm{kgBB}$, kelompok 4 diberikan ekstrak dosis $72,8 \mathrm{mg} / \mathrm{kgBB}$, kelompok 5 diberikan ekstrak dosis $145,6 \mathrm{mg} / \mathrm{kgBB}$. Tikus diberikan perlakuan selama 7 hari. Kadar kolesterol darah tikus diperiksa menggunakan Cholesterol Easy Touch. Hasil Penelitian didapatkan bahwa tidak ada penurunan kadar kolesterol pada kelompok 1, tetapi terjadi penurunan kadar kolesterol terhadap kelompok 2, 3, 4, dan 5 masing-masing sebesar 51,09\%, 42,59\%, 42,60\%, dan $50,59 \%$. Aktivitas penurunan kadar kolesterol pada ketiga kelompok uji penggunaan ekstrak daun kelor dengan dosis yang lebih besar dapat menurunkan kadar kolesterol darah tikus. Dapat disimpulkan ekstrak daun kelor dosis $145,6 \mathrm{mg} / \mathrm{kgBB}$ dapat menurunkan kadar kolesterol tikus sebesar 50,59\% namun lebih rendah bila dibandingkan dengan simvastatin dengan penurunan kadar kolesterol tikus sebesar 51,09\%.
\end{abstract}

Kata kunci : : Antihiperkolesterol, Moringa oleifera., Daun kelor

\begin{abstract}
Background Cholesterol is a fatty substance made in the liver and saturated fat in food. If the cholesterol level in the blood is too high, it will further increase the risk factors for coronary artery disease. The objective of this study was to determine the activity of Moringa oleifera extract in reducing cholesterol levels in Sprague Dawley male rats. Research methods this study was an in vivo experimental study using a pre-and post-test group design in NovemberDecember 2019. The research subjects were 30 Sprague Dawley male rats divided into 5 groups. Group 1 was given $0.5 \% \mathrm{CMC}$ and group 2 was given $0.18 \mathrm{mg}$ simvastatin. The test group was group 3 was given extract dose of $36.4 \mathrm{mg} / \mathrm{kgBW}$, group 4 was given extract dose of $72.8 \mathrm{mg} / \mathrm{kgBW}$, group 5 was given extract dose of $145.6 \mathrm{mg} / \mathrm{kgBW}$. Rats were treated for 7 days. Blood cholesterol levels of rats were examined using Easy Touch Cholesterol. The result showed that there was no decrease in cholesterol levels in group 1, but a decrease in cholesterol levels in groups 2, 3, 4, and 5 respectively by $51.09 \%, 42.59 \%, 42.60 \%$, and $50.59 \%$. The activity of reducing cholesterol levels in the three test groups using Moringa leaf extract with larger doses can reduce rat blood cholesterol levels. It can be concluded that Moringa leaf extract dose $145.6 \mathrm{mg} / \mathrm{kgBW}$ can reduce rat cholesterol levels by $50.59 \%$ but lower when compared to simvastatin with a decrease in rat cholesterol levels by $51.09 \%$.

Keywords: Antihypercholesterol, Moringa oleifera, Moringa leaves
\end{abstract}

Volume X No. 1 Juni $2020 \mathrm{Hal}-8$ 
PENDAHULUAN

Hiperkolesterol adalah suatu kondisi jumlah kolesterol di dalam darah melebihi batas normal. Kolesterol merupakan unsur penting dalam tubuh yang diperlukan untuk mengatur proses kimiawi di dalam tubuh, tetapi kolesterol dalam jumlah tinggi menyebabkan terjadinya aterosklerosis yang akhirnya akan berdampak pada penyakit jantung koroner (PJK) (Rebecca, dkk., 2014).

Hiperkolesterol dapat terjadi karena faktor genetik serta gaya hidup (life style) yang tidak sehat, mulai dari pola makan yang tidak seimbang sampai kurangnya aktivitas olahraga. Kadar kolesterol yang tinggi dapat disebabkan oleh sintesis kolesterol dan penyerapan kolesterol yang tinggi serta akibat konsumsi makanan tinggi lemak dan karbohidrat (Sudha, dkk., 2009; Hernawati, dkk., 2013).

Data WHO (World Health Organization) tahun 2015 memperlihatkan Penyakit Jantung Koroner (PJK) sebagai penyebab kematian utama di dunia, diperkirakan sekitar 8,7 juta orang di dunia meninggal karenanya (WHO, 2015). Berdasarkan data Riskesdas (Riset Kesehatan Dasar) tahun 2013 proporsi penduduk Indonesia dengan kadar kolesterol total di atas normal lebih tinggi pada perempuan $(39,6 \%)$ dibandingkan pada laki-laki $(30,0) \%$ dan di daerah perkotaan lebih tinggi dari pada daerah pedesaan (Depkes, 2013).

Indonesia dikenal akan kekayaan alamnya yang luar biasa sehingga negara Indonesia menduduki nomor dua dengan tanaman tradisional terbanyak setelah Brazilia. Tumbuhan yang ada di Indonesia dapat dimanfaatkan untuk kepentingan masyarakat. Dimasa lalu, bangsa Indonesia telah menggunakan berbagai ramuan dari daun, akar, buah, kayu, dan umbi-umbian untuk mendapatkan kesehatan dan menyembuhkan berbagai penyakit. Berbagai ramuan tradisional tersebut sering dikenal sebagai pengobatan herbal (Suparni \& Wulandari, 2012).
Obat tradisional dapat dijadikan sebagai terapi alternatif dari bahan alam yang memiliki efek samping relatif lebih rendah dan memiliki lebih dari satu efek farmakologi. Akhir-akhir ini, banyak dilakukan penelitian mengenai tanaman yang memiliki efek yang sama dengan obat sintetik namun efek samping yang lebih ringan, seperti umbi bawang putih, daun belimbing wuluh, rimpang kunyit, biji alpukat, dan daun salam (Mun'im dan Hanani, 2012). Selain itu, terdapat banyak penelitian yang menguji potensi herbal daun kelor untuk menangani hiperkolesterol, hyperlipidemia, dan hipertensi (Sri Handayani, 2017).

Daun kelor (Moringa oleifera) berperan sebagai anti hiperlipidemia karena mengandung alkaloid, saponin, filosterol, tannin, fenolik, dan flavonoid (Rajanandh, et al,. 2012). Flavonoid pada daun kelor mencegah oksidasi LDL dan menghambat aktivitas HMG-CoA Reduktase. Daun kelor juga mengandung vitamin $\mathrm{C}$ yang berperan dalam metabolisme lemak. Senyawa aktif pada daun kelor mempunyai aktivitas antioksidan yang sangat kuat dan mampu mencegah terjadinya LDL teroksidasi (Logu, 2005).

Penelitian sebelumnya mengenai efektivitas ekstrak etanol daun kelor (Moringa oleife) terhadap penurunan kadar kolesterol darah pada mencit (Mus musculus) jantan, menyebutkan bahwa semua dosis menunjukkan efek penurunan kadar kolesterol secara nyata berdasarkan perbandingan dengan kontrol negatif. Pada penelitian ini, efek yang terbaik ditunjukkan oleh konsentrasi $20,8 \mathrm{mg} / \mathrm{ml}$ (Andi, 2015).

Berdasarkan hal tersebut, penelitian ini bertujuan membuktikan manfaat daun kelor terhadap penurunan kadar kolesterol pada tikus jantan Sprague dawley yang diberi makanan tinggi kolesterol yaitu kuning telur puyuh dan CMC-Na sebagai kontrol negatif, dan dengan menggunakan obat penurunan kolesterol yang umum dipakai di masyarakat yaitu simvastatin sebagai kontrol positif. 


\section{METODELOGI PENELITIAN}

Penelitian ini merupakan penelitian yang bersifat eksperimental laboratorium, sedangkan rancangan atau desain penelitian menggunakan pretest dan post test control group design, Penelitian ini dilakukan di Laboratorium Farmakologi dan Laboratorium Kimia Bahan Alam STIK Siti Khadijah Palembang pada bulan November-Desember 2019.

Alat : Sonde, spuite, timbangan analitik, mortar, beaker glass, cawan petri, batang pengaduk, corong kaca, alat rotary evaporator, cawan porseline, waterbath, botol kaca, pipet tetes, spatel, alat cek kolesterol, alumunium foil, gunting bedah.

Bahan : Bahan yang digunakan dalam penelitian ini yaitu daun kelor (Moringa oleifera), tikus jantan Sprague dawley, CMC 0,5\%, simvastatin, kuning telur puyuh.

\section{Ekstraksi}

Ditimbang sampel 2000 gram dimasukkan dalam maserator, ditambahkan etanol $96 \%$ hingga terendam. Maserator ditutup dan terlindung dari sinar matahari langsung, dibiarkan selama 24 jam sambil diaduk sesekali, dan dipisahkan filtratnya. Filtrat yang diperoleh kemudian dievaporator dan diuapkan hingga diperoleh ekstrak kental. Ekstrak yang diperoleh ditimbang dengan menggunakan neraca analitik.

\section{Pembuatan Suspensi CMC 0,5\%}

Sebanyak 0,5g CMC ditaburkan kedalam lumpang yang berisi $30 \mathrm{ml}$ aquadest panas dan didiamkan selama 15 menit hingga memperoleh masa yang transparan lalu digerus sampai homogen. Selanjutnya diencerkan dengan aquadest dan dimasukkan ke dalam labu ukur 100 $\mathrm{ml}$.

\section{Pembuatan Pakan Tinggi Lemak}

Pakan tinggi lemak untuk meningkatkan kadar kolesterol diberikan setiap hari selama 7 hari. Pada penelitian sebelumnya yang dilakukan oleh Muhtadi dan kawan-kawan (2013) menggunakan pakan tinggi lemak yang terdiri dari 150 gram pakan standar (pellet), 20 gram kuning telur puyuh, dan 50 gram margarin. Cara pembuatannya yaitu margarin dipanaskan hingga leleh kemudian semua bahan dicampur dan diaduk sampai rata. Pakan tinggi lemak diberikan sebanyak 3 gram/hari.

\section{Pembuatan Simvastatin}

Dosis simvastatin untuk manusia $=10$ mg

Konversi dari manusia ke tikus $200 \mathrm{~g}=$ 0,018

Untuk tikus $200 \mathrm{~g}=10 \mathrm{mg}$ x $0,018=0,18 \mathrm{mg}$ Berat rata-rata tikus yang digunakan $=200 \mathrm{~g}$ Dosis tikus 200g $=200 / 200 \times 0,18=0.18$ $\mathrm{mg} / 200 \mathrm{~g}$ tikus

Volume maksimum pemberian oral pada tikus $=3-5 \mathrm{ml}$

Jika dalam 1 kali pemberian oral pada tikus $1 \mathrm{ml}$, maka

VOA - 0,18/1 ml (1 kali sonde) dibuat larutan stok $100 \mathrm{ml}$

Simvastatin ditimbang $18 \mathrm{mg}+10 \mathrm{ml} \mathrm{CMC}$ $\mathrm{Na} 0,5 \%$ + aquades ad $100 \mathrm{ml}$.

\section{Persiapan Hewan Uji}

Hewan uji yang digunakan adalah tikus jantan Sprague dawley yang sehat dengan bobot badan rata-rata 200 gram. Sebanyak 30 ekor yang dibagi ke dalam 5 kelompok perlakuan, tiap kelompok terdiri dari 6 ekor tikus putih jantan. Terlebih dahulu diadaptasikan selama 7 hari

\section{Rancangan Penelitan}

Semua hewan uji dipuasakan terlebih dahulu, diambil darah melalui ekor dan diukur kadar koleterol darah awal (Ha). Kemudian hewan coba diinduksikan dengan kuning telur puyuh selama 1 minggu, pada hari (H0) diukur kenaikan kadar kolesterolnya, pada hari ke-3 diukur lagi kadar kolesterolnya sampai hari ke-7. Kelompok 1: CMC (Kontrol Negatif) per oral. 
Kelompok 2: Simvastatin (Kontrol Positif) per oral.

Kelompok 3: Ekstrak etanol daun kelor dosis $36,4 \mathrm{mg} / \mathrm{KgBB}$ per oral.

Kelompok 4: Ekstrak etanol daun kelor dosis $72,8 \mathrm{mg} / \mathrm{KgBB}$ per oral.

Kelompok 5: Ekstrak etanol daun kelor dosis $145,6 \mathrm{mg} / \mathrm{KgBB}$ per oral.

\section{Pengukuran Kadar Kolesterol}

Alat ukur kolesterol diaktifkan dengan menekan tombol alat tersebut dan dilakukan kalibrasi. Strip dipasang pada alat tersebut. Darah diambil dari pembuluh darah vena pada ekor tikus kemudian diteteskan pada strip alat pengukur kolesterol dan kadar kolesterol darah tikus akan terukur secara otomatis. Hasilnya ditampilkan pada monitor berupa angka.

\section{HASIL DAN PEMBAHASAN}

Hasil identifikasi skrining fitokimia daun kelor yang dilakukan dapat dilihat pada tabel dibawah ini :

Tabel 1. Hasil Skrining Fitokimia

\begin{tabular}{lc}
\hline Senyawa Metabolit & Hasil Daun \\
\hline Flavonoid & + \\
\hline Saponin & + \\
\hline Triterpenoid & + \\
\hline Steroid & + \\
\hline Fenol & + \\
\hline
\end{tabular}

Tabel 2. Persentase Penurunan Kadar Kolesterol Darah Tikus.

$\begin{array}{clll}\text { Perlakuan } & \text { H0 } & \text { H-7 } & \% \\ & & & \\ \text { Kelompok 1 } & 226,4 \pm & 235,2 \pm & - \\ \text { Kontrol Negatif } & 21,57 & 15,54 & \\ \quad \text { CMC } & & & \\ \text { Kelompok 2 } & 233 \pm & 132,6 \pm & 51,09 \\ \text { Kontrol Positif } & 38,29 & 31,59 & \\ \text { Simvastatin } & & & \\ & & & \\ \text { Kelompok 3 } & 254 \pm & 145,8 \pm & 42,59 \\ \text { Daun Kelor } & 56,76 & 11,71 & \\ \text { 36,4 mg/kgBB } & & & \\ \text { Kelompok 4 } & 242,2 \pm & 139 \pm & 42,60 \\ \text { Daun Kelor } & 83,62 & 12,70 & \\ \text { 72,8 mg/kgBB } & & & \\ \text { Kelompok 5 } & 268,4 \pm & 132,6 \pm & 50,59 \\ \text { Daun Kelor } & 44,35 & 28,20 & \\ \text { 145,6 mg/kgBB } & & & \end{array}$

Hasil analisis didapatkan bahwa tidak ada penurunan kadar kolesterol pada kelompok 1 sebagai kontrol negatif. Hal ini menunjukkan bahwa CMC tidak memiliki aktivitas menurunkan kadar kolesterol darah. Pada tabel 3.2 terlihat bahwa pemberian ekstrak daun kelor dapat menurunkan kadar kolesterol darah tikus. Data menunjukkan bahwa semakin tinggi dosis ekstrak yang diberikan, semakin tinggi juga penurunan kadar kolesterol darah tikus. Penurunan tertinggi terjadi pada pemberian ekstrak dosis 145,6 $\mathrm{mg} / \mathrm{kgBB}$ yaitu sebesar 50,59\%. Tetapi penurunan tersebut tidak lebih tinggi daripada penurunan kadar kolesterol darah tikus setelah pemberian simvastatin sebagai kontrol prositif. Simvastatin dapat menurunkan kadar kolesterol darah tikus hingga 51,09\%.

Aktivitas ekstrak daun kelor dalam menurunkan kadar kolesterol darah tikus disebabkan karena daun kelor berperan sebagai anti hiperlipidemia karena mengandung alkaloid, saponin, filosterol, tannin, fenolik, dan flavonoid (Rajanandh, et al,. 2012). Flavonoid pada daun kelor mencegah oksidasi LDL dan menghambat aktivitas HMG-CoA Reduktase. Daun 
kelor juga mengandung vitamin $\mathrm{C}$ yang berperan dalam metabolisme lemak. Senyawa aktif pada daun kelor mempunyai aktivitas antioksidan yang sangat kuat dan mampu mencegah terjadinya LDL teroksidasi (Logu, 2005).

\section{KESIMPULAN DAN SARAN}

\section{Simpulan}

Berdasarkan hasil penelitian yang dilakukan maka dapat disimpulkan bahwa ekstrak etanol daun kelor (Moringa oleifera) memiliki aktivitas menurunkan kadar kolesterol pada tikus jantan Sprague Dawley. Ekstrak etanol daun kelor (Moringa oleifera) pada dosis 36,4, 72,8, dan 145,6 mg/KgBB memiliki efek antihiperkolesterol dengan nilai persentase penurunan kolesterol masing-masing sebesar $42,59 \%, 42,60 \%$ dan 50,59\%. Hal ini membuktikan bahwa semakin tinggi dosis ekstrak yang diberikan maka persentase penurunan kadar kolesterol total dalam darah juga akan semakin besar.

\section{Saran}

Disarankan untuk penelitian selanjutnya perlu dilakukan penelitian lebih lanjut untuk mengetahui aktivitas antikolesterol dari senyawa aktif hasil isolasi daun kelor (moringa oleifera).

DAFTAR PUSTAKA

Aditya, 2011. Hewan Uji Percobaan Tikus Putih Galur Sprague dawley. Padang : Universitas Baiturrahman.

Agoes, G. 2007. Teknologi Bahan Alam. Bandung: ITB Press.

Ansel, H. C. 2014. Bentuk Sediaan Farmasetis dan Sistem Penghantaran Obat. 9 th Ed, diterjemahkan oleh $\mathrm{H}$. Afifah dan T. Ningsih. Jakarta: EGC.

Binawati \& Amilah. 2013. Kandungan Tanaman Kelor. Registrasi Obat Tradisional.

Departemen Kesehatan RI. 2000. Parameter Standar Umum
Ekstrak Tumbuhan Obat.

Jakarta: Departemen Kesehatan Republik Indonesia.

Ditjen POM. 1995. Farmakope Indonesia. Edisi IV. Jakarta: Departemen Kesehatan Republik Indonesia.

Djamal, Rachman. 2012. Kimia Bahan Alam: Prinsip-prinsip Isolasi dan Identifikasi. Padang: Universitas Baiturrahman.

Gunawan, dkk. 2010. Ilmu Obat Alam (Farmakognosi). Jilid 1. Jakarta: Penebar Swadaya.

Harbone, J. B. 2006. Metode Fitokimia, Edisi II, Diterjemahkan oleh K. Padmawinata dan I. Soediro. Bandung: Penerbit ITB.

Jones, W. P. \& Kinghorn, A. D. 2006. Extraction of Plant Secondary Metabolites. In : Sarker, S. D., Latif, Z., dan Gray. A. I., eds. Natural Products Isolation. 2 Ed. New Jersey: Humana Press.

Kristianti, A. N., Aminah, N. S., Tanjung, M \& Kurniadi, B. 2008. Buku Ajar Fitokimia. Surabaya: Jurusan Kimia Laboratorium Kimia Organik FMIPA Universitas Airlangga.

Kristianti \& Nurlela. 2018. Pengaruh Pemberian Filtrat Buah Kelor (Moringa oleifera) terhadap Kadar Kolesterol pada hewan uji. Media Bina Ilmiah.

Laurenede \& Bachrach, 1964. Tabel konversi Dosis antara jenis subjek uji.

Merry. 2017. Sifat-sifat kolesterol sebagai sumber kalori serta memberikan nilai tambah terhadap cita rasa makanan.

Mukhriani. 2015. Uji efektivitas ekstrak etanol daun kelor (Moringa oleifera) terhadap penurunan kadar kolesterol darah pada mencit (Mus Musculus) jantan.

Muhtadi, dkk. 2013. Pengembangan Potensi Ekstrak Kulit Buah Rambutan sebagai Bahan Obat 
Herbal Antihiperkolesterol. Biomedika.

Murray, R. K., Granner, D. K.Mayes, P. A dan Rodwell, V. W. 2003. Biomedik Harper. 25 th Ed. Jakarta: EGC.

Nurrahmani, U. 2012. Stop! Kolesterol Tinggi. Yogyakarta: Familia.

Peraturan Menteri Kesehatan Republik Indonesia No. 007.2012. Registrasi Obat Tradisional.

Resuddin., 2011. Simvastatin.. Bandung: ITB.

Rebecca, dkk. 2014. Pemanfaatan Minuman Serbuk Instan Kayu Manis (Cinnamomumburmanii BI) untuk Menurunkan Kadar Kolesterol Total Darah pada Tikus Putih (Rattus norvegicus). Yogyakarta:

Fakultas

Teknobiologi, Universitas Atma Jaya Yogyakarta.

Robinson, T. 1995. Kandungan Organik Tumbuhan Obat Tingi.

Diterjemahkan oleh Kokasih Padmawinata. Bandung: ITB.

Rollof, et al., 2009. Tanaman Kelor beserta khasiatnya dan klasifikasi

Tanaman Kelor. Yogyakarta:

Fakultas Teknobiologi,

Universitas Atma Jaya Yogyakarta.

Sachan, D. In-Vitro and In-Vivo Efficacy of Moringa oleifera Plant Constituents in Urolithiasis As Antilithiaric Drug. India: Institute of Pharmacy, Bundelkhand University, Jhansi, Uttar Pradesh, India IJPSR. 2011. Vol. 2., issue 7.

Soesilo, S. 2014. Sosiologi Lingkungan. Jakarta: Rajawati Press.

Sudha, M. R., Prashant, C., Kalpana, D., Sekhar, B. dan Kalser, J. 2009. Probiotics as Complementary Therapy for Hypercholesterolemia. Biology and Medicine. Volume 1.

Thitilertdecha, N., Teerawutgulrag, A., Rakariyatham. N. 2008.
Antioxidant and Antibacterial Activities of Nephelium Lappaceum L. Extracts. Food Science and Technology. Elservier.

Utariningsih, D. 2007. Dekok rambut jagung (zea mays) efektif dalam menurunkan kadar kolesterol tikus putih (rattus norvegicus). Malang:

Universitas Muhammadiyah Malang.

WHO. 2015. Library CataloguingPublication Data. Heart: Teachnical Package for Cardiovascular Disease Management in Primary Heart Care. Switzerland: WHO Press.

Widowati. 2014. Tanaman Kelor beserta khasiatnya dan klasifikasi Tanaman Kelor. Yogyakarta: Fakultas Teknobiologi, Universitas Atma Jaya Yogyakarta. 